\title{
Inductively Coupled Plasma Mass Spectrometry with an Electrically Floating Sampling Interface
}

\author{
Ke Hu* and R. S. Houk \\ Ames Laboratory-U.S. Department of Energy, Department of Chemistry, Iowa State University, Ames, Iowa, \\ USA
}

In conventional inductively coupled plasma mass spectrometry devices, the sampler and skimmer are grounded. In this work, modest DC voltages $(+10$ to $+50 \mathrm{~V})$ are applied to either (or both) sampler and skimmer. Alternatively, the skimmer is biased, and the sampler is merely left floating. The latter arrangement improves sensitivity for $\mathrm{Co}^{+}$by sixfold, provides nearly the same molar sensitivity for $\mathrm{Co}^{+}, \mathrm{Rh}^{+}$, and $\mathrm{Ho}^{\prime}$, and extends the upper end of the linear dynamic range to approximately $100 \mathrm{ppm}$. These changes to the interface do not affect the background perceptibly. The relationship between applied potential and the potential actually measured on the sampler and skimmer is also discussed. (J Am Soc Mass Spectrom 1993, 4, 733-741)

A lthough inductively coupled plasma mass spectrometry (ICP/MS) has very good detection limits for most elements $\left(1-50 \mathrm{ng} \mathrm{L}^{-1}\right)$, it still suffers from inefficient collection and transmission of ions. The sensitivity of current commercial ICP/MS systems is approximately $1 \times 10^{6}-1 \times 10^{8}$ counts $\mathrm{s}^{-1}$ $\mathrm{ppm}^{-1}$. For an clement of atomic weight $100 \mathrm{~g} \mathrm{~mol}^{-1}$, this corresponds to the introduction of $10^{6}-10^{8}$ analyte atoms to the plasma to detect one analyte ion. The low efficiency derives largely from the relatively poor transmission of the ion optics due to severe space charge effects $[1,2]$ and from the limited transmission of the skimmer and mass filter. Space charge problems are also believed to cause matrix interference effects. Generally, heavy analyte ions are suppressed less severely than light ones, and heavy matrix ions suppress analyte signals more extensively than light matrix ions [1-5].

The space charge limit ( $I_{\max }$, in microamperes) for an ion current focused through a cylinder of diameter $D$ and length $L$ (both in centimeters) is given by

$$
I_{\max }=0.9(\mathrm{~m} / z)^{1 / 2} V^{3 / 2}(D / L)^{2}
$$

where $m / z$ is the mass-to-charge ratio of the major ion (relative to ${ }^{12} \mathrm{C}=12 \mathrm{u}$ ), and $V$ is the ion energy (in electron volts) [1,2]. Equation 1 suggests that accelerating the ions to higher energies would improve ion transmission and attenuate mass discrimination by overcoming the space charge problem [6]. Usually, the metal interface cones through which the ions are

\footnotetext{
*Present address: Thermo Jarrell-Ash Corp., B E. Forge Parkway Franklin, MA 02038-3148.

Address reprint requests to R. S. Houk, Department of Chemistry, lowa State University, Ames, LA 50011.
}

extracted are connected to ground potential. Electrically floating one or both of these cones at various potentials could accelerate the ions and therefore improve the ion transmission. Bradshaw et al. [7] and Morita et al. [8] apply the same high voltage (about $+5 \mathrm{kV}$ ) to both the sampler and skimmer. A doublc-focusing mass analyzer is used so that polyatomic ions can be separated from analyte ions. At unit mass resolution, ion transmission with these instruments is actually higher than that obtained with most quadrupole devices [9], so perhaps space charge effects are mitigated somewhat by accelerating the ions to high kinetic energies.

Several other studies with quadrupole-type ICP/MS devices pertain to the general idea of changing the potential through which ions are extracted. Some early ICP/MS devices, particularly the PQ1 from VG Elemental (Winsford, Cheshire, England), used an optional negative voltage $(0$ to $-50 \mathrm{~V})$ on both sampler and skimmer. It was thought that this arrangement minimized the secondary discharge [10]. Subsequently, it was found that the plasma potential and secondary discharge could be controlled by other methods, such as reduction of water loading or adjustment of plasma operating conditions [11, 12], so that present quadrupole ICP/MS devices simply use the conventional grounded interface.

Turner [13] accelerates ions to high kinetic energy behind the skimmer by using another metal cone at $-2 \mathrm{kV}$. He reports that sensitivities for light ions are improved compared with other ICP/MS instruments; a variety of elements with different masses have comparable molar sensitivities. Turner also states that matrix effects are minimized with this interface arrangement. 
Douglas $[14,15]$ applies a radio frequency (RF) voltage to the sampler and/or skimmer. Arcing at the sampler orifice is eliminated by applying an RF bias to the sampler. When the center-tapped load coil [16] is used and the sampler is grounded, the signal is also improved substantially by careful adjustment of the phase and amplitude of the RF bias applied to the skimmer [15].

In this work, modest positive DC voltages $(10-50 \mathrm{~V})$ are applied to the sampler or skimmer cones, and a quadrupole mass analyzer is used. Alternatively, the sampler is simply left floating (i.e., it is not connected deliberately to any voltage source or to ground). Ion transmission and calibration linearity are improved, and mass bias is greatly reduced by these arrangements $[17,18]$.

\section{Experimental}

\section{ICP / MS Apparatus}

A schematic of the ICP/MS instrument used in this work is shown in Figure 1. This instrument and some components have been described in detail elsewhere [19-21]. Operating conditions are identified in Table 1.

Sample solutions were nebulized with a continuous-flow ultrasonic nebulizer $[22,23]$. The solutions were delivered with a peristaltic pump at a rate of $1.5 \mathrm{~mL}$ min $^{-1}$. The aerosol was desolvated in a Pyrex heating tube at $140{ }^{\circ} \mathrm{C}$, followed by a condenser at $0^{\circ} \mathrm{C}$ [17]. Unlike $\mathrm{Hu}$ et al. [24, 25], RF-only quadrupoles were not used either before or after the mass analyzer. Ions were detected with a Channeltron electron multiplier (model 4830A, Galileo Electro-Optics Corp., Sturbridge, MA).

\section{Interface}

A typical ICP/MS sampling interface is shown in Figure 2. The sampling cone is made of nickel. The orifice is enlarged to a $1.31-\mathrm{mm}$ diameter from the

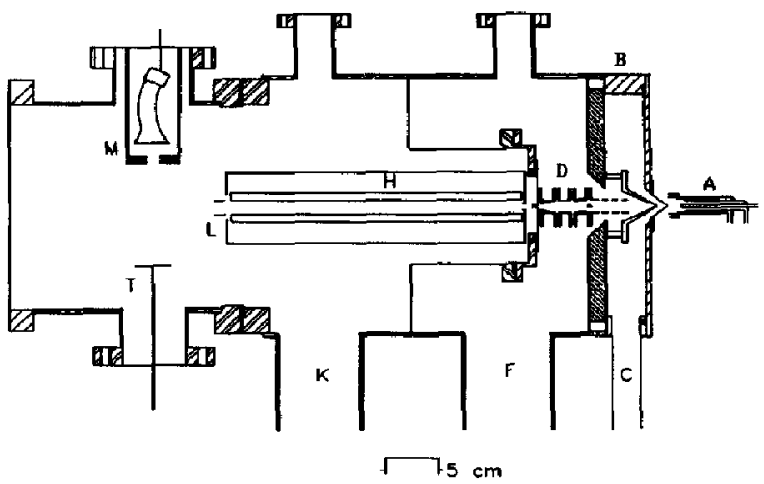

Figure 1. Schematic of ICP/MS instrument: (A) ICP; (B) ion extraction interface; (C) port to rotary purnp; (D) ion lens; (F and K) ports to diffusion pumps; $(H)$ quadrupole mass analyzer; (L) ion exit lens; (M) Channeltron detector; (T) ion deflection plate.
Table 1. Optimuma operating conditions for ICP/MS device

\begin{tabular}{ll}
\hline \multicolumn{1}{c}{ Component } & Operating condition \\
\hline \hline Plasma forward power & $1.30 \mathrm{~kW}$ \\
Plasma reflected power & $<5 \mathrm{~W}$ \\
Plasma argon flow & $17 \mathrm{~L} \mathrm{~min}^{-1}$ \\
Outer & 0 \\
Auxiliary & $1.30 \mathrm{~L} \mathrm{~min}^{-1}$ \\
Aerosol & $13 \mathrm{~mm}$ from load coil, \\
Sampling position & on center \\
& 2.35 torr \\
Expansion chamber pressure & $5 \times 10^{-4}$ torr \\
Second-stage pressure & $2 \times 10^{-5}$ torr \\
Third-stage pressure & $-250 \mathrm{~V}$ \\
lon lens settings (Figure 2) & $-10 \mathrm{~V}$ \\
First cylindrical lens & $-30 \mathrm{~V}$ \\
Second cylindrical lens & $-170 \mathrm{~V}$ \\
Third cylindrical lens & $-14 \mathrm{~V}$ \\
Fourth cylindrical lens & $-100 \mathrm{~V}$ \\
Photon stop & $-20 \mathrm{~V}$ \\
Differential pumping orifice & $-150 \mathrm{~V}$ \\
ELFS ${ }^{5}$ lens & $+700 \mathrm{~V}$ \\
lon exit lens & $-250 \mathrm{~V}$ \\
Ion deflecting plate & $-3000 \mathrm{~V}$ \\
Detector housing aperture & $-2500 \mathrm{~V}$ \\
Channeltron electron multiplier & $+1.0 \mathrm{~V}$ \\
Pulse counting & \\
lon current & \\
Quadrupole rod mean DC potential & \\
\hline
\end{tabular}

${ }^{a}$ Defined as the plasma conditions, sampling position, and ion lens voltages that yielded maximum sensitivity for $\mathrm{Co}^{+}$

usual $1.0 \mathrm{~mm}$. The diameter of the skimmer orifice is also $1.31 \mathrm{~mm}[24,25]$. The angles and other dimensions of the sampler and skimmer are described elsewhere [19]. The distance between the sampler and skimmer orifices is $11 \mathrm{~mm}$. At this position, the skimmer tip is

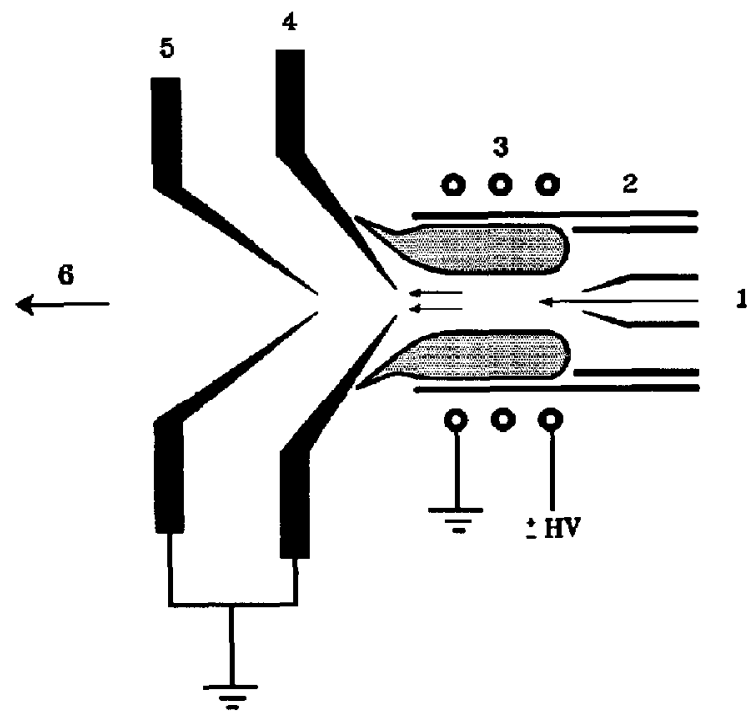

Figure 2. Typical ICP/MS sampling interface (both sampler and skimmer grounded): (1) sample aerosol; (2) ICP torch; (3) load coil; (4) sampler; (5) skimmer; (6) ion beam to mass analyzer. 
two-thirds of the way from the sampling orifice to the onset of the Mach disk, which yields optimum sensitivily, as described previously by Douglas and French [26].

Three specific arrangements for floating parts of the interface were studied. In Figure $3 a$, the same DC bias voltage is applied to both the sampler and skimmer. In the following discussion, the term "sampler and skimmer biased together" refers to this arrangement, which is the same as that used for magnetic sector mass spectrometers with the ICP $[7,8]$. Figure $3 \mathrm{~b}$ shows a second arrangement (termed "sampler floating and skimmer biased") in which the sampler is allowed to float; a DC bias voltage is applied only to the skimmer. Naturally, the sampler is cooled by water supplied from a grounded metal faucet through plastic watercooling lines. Thus, the sampler is connected to ground through the water-cooling lines, which have an electri-

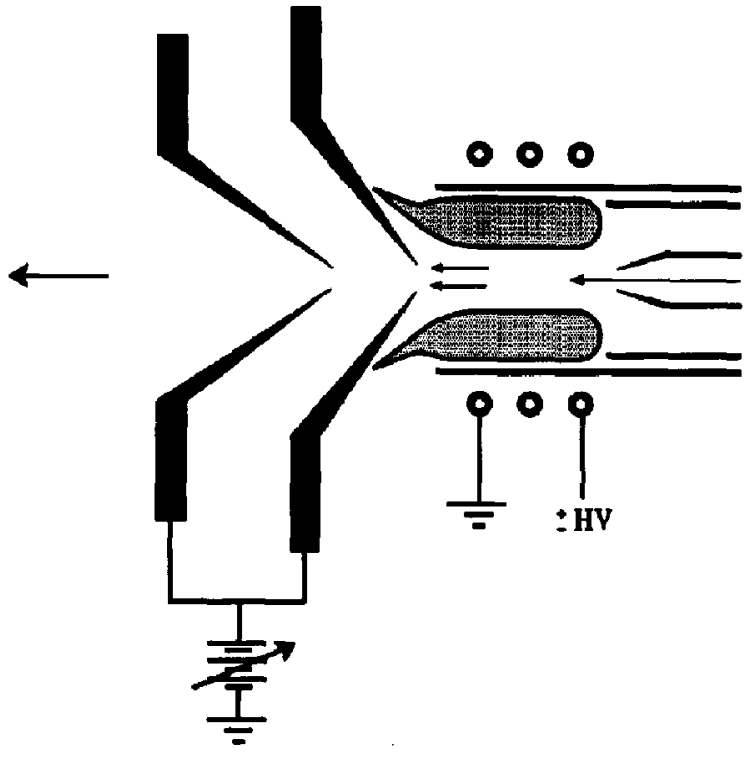

a
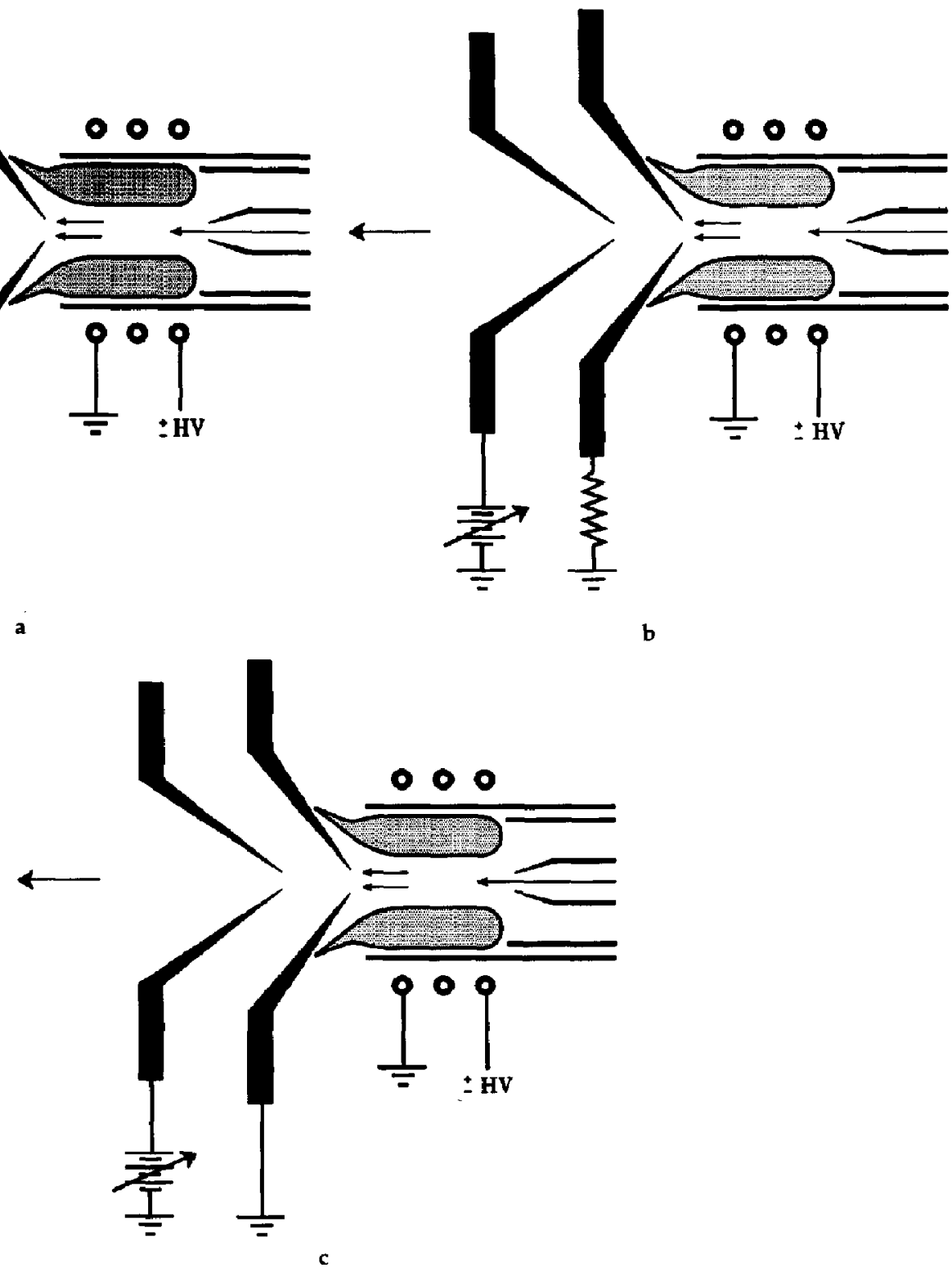

Figure 3. Diagrams of floating arrangements of sampling interface: (a) sampler and skimmer biased together; (b) sampler floated and skimmer biased; (c) sampler grounded and skimmer biased. $H V=$ high voltage applied to load coil . 
cal resistance of approximately $20 \mathrm{M} \Omega$. Because of the relatively high resistance, for all practical purposes the sampler is not connected to ground and therefore floats.

Figure $3 \mathrm{c}$ shows a third arrangement of sampling interface (termed "sampler grounded and skimmer biased") in which the sampler is grounded, and a DC bias voltage is applied only to the skimmer. The skimmer is bolted to the main vacuum chamber by nylon bolts and is insulated at its base with a Teflon spacer. The sampler flange is bolted to the expansion chamber in the same way. The sampler and skimmer are insulated from each other, except that both share the same water-cooling line (20-M $\Omega$ resistance to ground).

There are several ways to ground both sampler and skimmer flanges. Usually, the sampler and skimmer are bolted directly to the grounded vacuum system with stainless steel bolts. This scheme is not convenient for switching from a grounded arrangement (Figure 2) to one of the floating arrangements (Figure 3). Alternatively, the sampler and skimmer flanges are grounded to the vacuum chamber only through copper wires (5-10 cm long) at four opposite positions along the perimeter of the copper flange that supports and cools the sampler (Figure 1).

\section{Ion Lens}

Ions passing through the skimmer ( $A_{t}$ Figure 4) enter the first stainless steel cylinder (1, Figure 4). Numerous holes are drilled in the side wall of the cylinder, so that neutral atoms can be evacuated. The second and third electrodes ( 2 and 3 , Figure 4 ) of the lens are also stainless steel cylinders, but the inside diameter of the sccond electrode is $2.5 \mathrm{~cm}$, twice that of the third electrode. A small conical photon stop (7, Figure 4) is placed in the center after the second cylinder. The fourth electrode of the ion lens (4, Figure 4) is tapered; the entrance is $12.7 \mathrm{~mm}$ in diameter, and the exit is

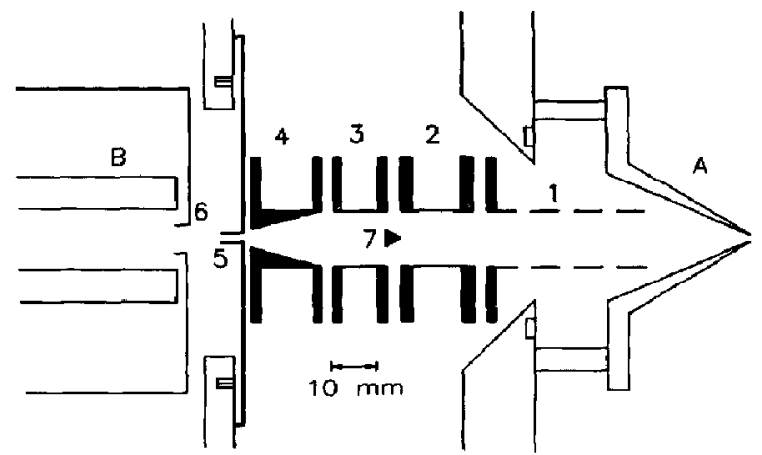

Figure 4. Schematic of ion lens system: (A) skimmer; (B) quadrupole mass analyzer; $(1-4)$ first to fourth electrodes of ion lens; (5) differential pumping orifice; (6) ELFS ${ }^{(6)}$ lens into rod housing; (7) photon stop.
$6.4 \mathrm{~mm}$ in diameter. Finally, ions pass through the differential pumping orifice (5, Figure 4 ), which is a tube $2.50 \mathrm{~mm}$ in diameter $\times 6.4 \mathrm{~mm}$ in length.

The voltages applied to each electrode are identified in Table 1. Note that the photon stop is biased separately from the other electrodes. The voltage settings listed are those that yield maximum ion signal for ${ }^{59} \mathrm{Co}^{+}$with interface $\mathrm{B}$ (sampler floating and skimmer biased at $+30 \mathrm{~V}$, Figure $3 \mathrm{~b})$. The lens voltages required to maximize signal for the other interfaces are not greatly different from those shown in Table 1.

The lens shown in Figure 4 differs in minor respects only from lenses used in common commercial instruments $[27,28]$. The main differences are that (1) the photon stop is conical, not a flat disk; and (2) the cylinder upstream from the differential pumping orifice is tapered. We did not evaluate the potential benefits of floating the interface with other lens arrangements.

\section{Data Acquisition}

Detection limits were measured by the procedure described previously by Douglas [14]. The detection limits represented the solution concentrations necessary to yield a net peak height equivalent to three times the standard deviation of the background. Background was measured at the mass-to-charge ratio values of interest during nebulization of a blank solution. Signals were measured in the multichannel scanning mode [27]. The dwell time was $50 \mu$ s $^{\text {address }}{ }^{-1}$ for 4096 addresses over a mass window 20 mass-to-charge ratio units wide. Sensitivity, detection limits, and mass discrimination were measured by pulse counting. A preamplifier (model 1763) and an amplifierdiscriminator (model 1762) (Photochemical Research Associates, London, Ontario, Canada) were used for ion counting.

At higher ion signal levels, ion current was measured for determination of calibration curves. The ana$\log$ output of the electron multiplier was fed into a current-to-frequency converter (model 151, Analog Technologies Inc, Irwindale, CA). The TTL pulses $(0-+5 \mathrm{~V})$ from the converter were counted by a multichannel analyzer with a dwell time of $50 \mu$ shannel $^{-1}$. To compare linear dynamic ranges fairly, the ion current from $20 \mathrm{Ppm}$ Co was adjusted to nearly equal sensitivity for each interface arrangement by adjusting the detector bias voltage.

Voltages on the sampler and skimmer were measured with a voltmeter (model ME-550, Digital Multimeter, SOAR Corporation, Japan). Ion kinetic energies were measured by applying a positive stopping voltage as the mean $\mathrm{DC}$ bias to the quadrupole mass filter [29-31]. The stopping voltage necessary to attenuate the ion signal to $5 \%$ of the original signal level was measured and is hereinafter referred to as "maximum ion energy." 


\section{Standards and Solutions}

Standard solutions were $0.1 \mathrm{mg} \mathrm{L^{-1 }}$ of each element unless noted otherwise. They were prepared by diluting aliquots of commercial stock solutions ( $1000 \mathrm{ppm}$ ) (Fisher, Fair Lawn, NJ) with distilled deionized water (18 M $\Omega$ ) (Barnstead, Newton, MA).

\section{Results and Discussion}

\section{Sensitivity and Detection Limits}

For this discussion, sensitivity is taken to be the ion signal per unit concentration of analyte, which is equivalent to the slope of the calibration curve. The term "relative sensitivity" refers to the sensitivity obtained for a given element with one of the new interface arrangements (Figure 3) divided by that obtained for the same element with the interface grounded by copper wires, as shown in Figure 2.

As shown in curve $\mathrm{A}$ of Figure $5, \mathrm{Co}^{+}$sensitivity is improved modestly (up to fourfold) by applying the same DC voltages (approximately $20 \mathrm{~V}$ ) to both sampler and skimmer. 'The sensitivity is improved by a factor of 6 by floating the sampler and applying a $D C$ voltage of $30-40 \mathrm{~V}$ to the skimmer (curve B, Figure 5). The signals are improved by a factor of 5 by grounding the sampler and applying approximately $20 \mathrm{~V}$ to the skimmer (curve $C$, Figure 5).

The sensitivities and detection limits in Table 2 were collected under the optimal operating conditions for each interface arrangement. Actually, the ion lens settings, plasma power, and aerosol gas flow rates that

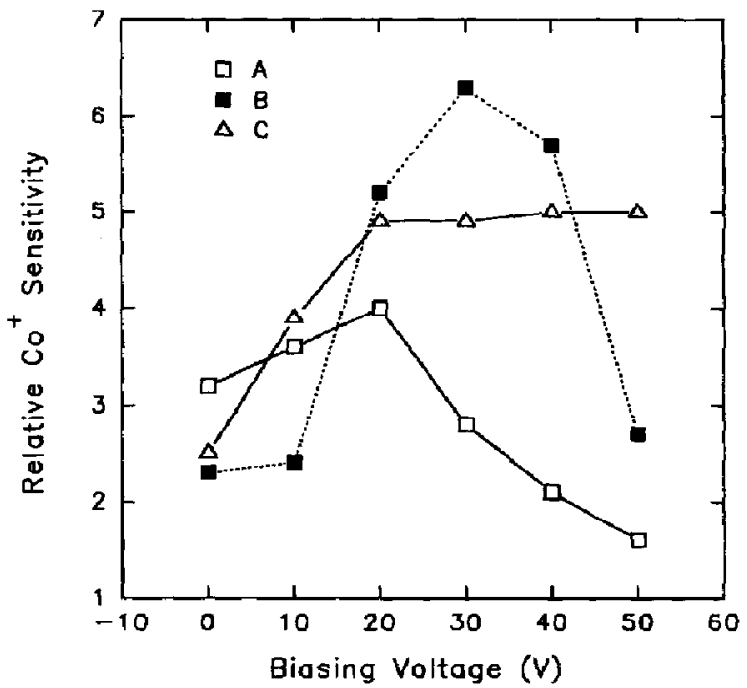

Figure 5. Relative $\mathrm{Co}^{+}$sensitivity as a function of biasing voltage with interface arrangements: (A) sampler and skimmer biased together; (B) sampler floated and skimmer biased; and (C) sampler grounded and skimmer biased. yield maximum $\mathrm{Co}^{+}$signals are comparable for all arrangements. Higher positive voltages (up to $100 \mathrm{~V}$ ) can be applied to the interface if the ion lens voltages are adjusted to reoptimize ion transmission. The $\mathrm{Co}^{+}$ sensitivities shown in Figure 5 and Table 2 are the best sensitivities obtainable with the lens voltages reoptimized to maximize signal for $\mathrm{Co}^{+}$after each change to the interface.

At first it may seem surprising that application of positive voltages to the interface should increase the signal for positive ions instead of merely repelling ions and preventing them from passing through the sampler and skimmer; however, the reader should note that positive ions can even pass through the high positive voltage (approximately $+5 \mathrm{kV}$ ) on the interface of a double-focusing ICP/MS device [7, 8]. Either the plasma floats up to this high voltage or the sheaths around the inner edges of the sampler and skimmer shield the charged particles from the voltage applied to the interface [26], or both. Presumably, the entrainment of ions in the gas flowing into the sampler, and the numerous collisions with neutrals that occur in the early phases of this flow, also draw the ions through the sampler despite the positive potential barrier therein [26].

For either floating interface, sensitivities for $\mathrm{Co}^{+}$are in the range $4.0 \times 10^{6}-6.0 \times 10^{6}$ counts $\mathrm{s}^{-1} \mathrm{ppm}^{-1}$, and detection limits are in the range 10-20 parts per trillion (pptr). Sensitivities and detection limits are improved by a factor of 4-6 with either floating interface arrangement. The best arrangement is perhaps the one with the floating sampler and biased skimmer (interface B), which improves ion signal by a factor of 6 . The interface arrangement does not affect the background, which is $150 \pm 20$ counts $^{-1}$ in all cases.

The leftmost points in Figure 5 also show that the relative sensitivity remains at a value of $2-3$, even when the bias voltage is set at zero. Thus, the ion signals are two or three times higher at $0 \mathrm{~V}$ for all three interface arrangements compared with the signals obtained when both sampler and skimmer are

Table 2. Sensitivity and detection limit for ${ }^{59} \mathrm{Co}^{+}$in floating interface systems and grounding interface system

\begin{tabular}{|c|c|c|}
\hline Interface arrangement & $\begin{array}{c}\text { Sensitivity } \\
\text { (counts } \mathrm{s}^{-1} \mathrm{ppm}^{-1} \text { ) }\end{array}$ & $\begin{array}{c}\text { Detection limit } \\
(p p t r)^{\mathrm{a}}\end{array}$ \\
\hline $\begin{array}{l}\text { Sampler and skimmer } \\
\text { grounded } \\
\text { (Figure 2) }\end{array}$ & $1.0 \times 10^{6}$ & 60 \\
\hline $\begin{array}{l}\text { Sampler and skimmer } \\
\text { biased together } \\
\text { (Figure 3a) }\end{array}$ & $4.0 \times 10^{6}$ & 15 \\
\hline $\begin{array}{l}\text { Sampler floated and } \\
\text { skimmer biased } \\
\text { (Figure 3b) } \\
\text { Sampler grounded and } \\
\text { skimmer biased } \\
\text { (Figure 3c) }\end{array}$ & $6.0 \times 10^{6}$ & 10 \\
\hline
\end{tabular}

apptr, parts per trillion. 
grounded to the vacuum system through the usual metal bolts. Apparently, grounding the interface to the vacuum system is not the same as grounding it to the voltage supply at $0 \mathrm{~V}$ because the latter arrangement yields higher ion signals.

\section{Linear Dynamic Range}

Linearity at low concentrations is not normally a problem in ICP/MS [27], so dynamic range is evaluated here by measuring calibration curves for relatively concentrated solutions ( $\geq 20 \mathrm{ppm})$. As shown in Figure 6 , the signal for $\mathrm{Co}^{+}$with the grounded interface is low and actually drops as concentration increases above $80 \mathrm{ppm}$. The $Y$ intercept of this curve does not pass through zero because the curve has probably already rolled over at $20 \mathrm{ppm}$. The curve obtained with the sampler floating and skimmer biased at +10 $V$ is linear to at least $60 \mathrm{ppm}$. Similar improvements in linear dynamic range are obtained with interfaces $A$ and $C$ as well.

Figure 6 also shows that the linear dynamic range is extended to at least $100 \mathrm{ppm}$ when the floating voltage is raised from 10 to $30 \mathrm{~V}$. Similar observations could be seen with interface A (sampler and skimmer biased together); however, the linear dynamic range obtained with the sampler grounded and skimmer biased is not influenced by the voltage applied to the skimmer if the voltage is above $20 \mathrm{~V}$. The curves with this arrangement are linear to at least $100 \mathrm{ppm}$ if the bias voltage is above $20 \mathrm{~V}$.

Extension of the linear dynamic range of ICP/MS to approximately $100 \mathrm{ppm}$, as shown in Figure 6, is not of obvious analytical utility. These devices are seldom, if ever, used to quantify elements at such high concentra-

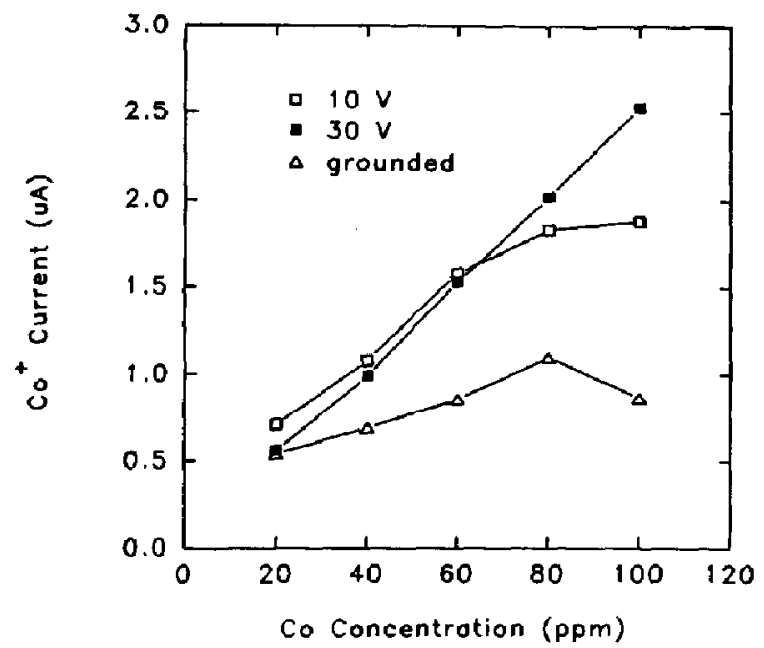

Figure 6. Linear dynamic range for conventional interface (sampler and skimmer grounded) and for interface arrangement $B$ (sampler floated and skimmer biased) at $10 \mathrm{~V}$ (口) or $30 \mathrm{~V} \mathrm{(a)}$ tions. However, this improvement in linear dynamic range is very valuable when an ICP/MS device is used for ion deposition or ion implantation [18], for which the objective is to make the ion beam as intense as possible. "Rollover" of calibration curves at concentrations greater than or equal to $50 \mathrm{ppm}$ is a severe problem in such experiments.

\section{Mass Bias}

Consider the approximately 70 elements with ionization energies below $8 \mathrm{eV}$. Saha calculations of the degree of ionization indicate that the ICP should produce a high, uniform yield of atomic ions from these elements, with relatively few doubly charged ions [32]. Thus, if variations in isotopic abundance are accounted for, the sensitivity for such elements should be similar. Unfortunately, most ICP/MS devices discriminate substantially against lighter ions, a problem commonly called "mass bias" in ICP/MS parlance. Dispersion of the ion beam by space charge effects is probably one cause of mass bias because lighter ions tend to be deflected more extensively and are thus collected with poorer efficiency [1, 2]. Other effects, such as mass discrimination by the quadrupole and detector, probably also contribute to the mass bias problem $[27,33]$.

In this study, the elements $\mathrm{Co}(m / z 59), \mathrm{Rh}(m / z$ 103), and Ho $(\mathrm{m} / z$ 165) were chosen for mass bias measurements because they are monoisotopic, and their degree of ionization should be $90-100 \%[27,32]$. A solution containing each element at $100 \mathrm{ppb}$ is nebulized. The measured count rates are divided by the molar concentrations (in millimolar units) to account for the differences in atomic weight.

Molar sensitivities for ${ }^{59} \mathrm{Co}^{+},{ }^{103} \mathrm{Rh}^{+}$, and ${ }^{165} \mathrm{Ho}^{+}$ are shown in Table 3. With the conventional interface (sampler and skimmer grounded), the molar sensitivity for ${ }^{59} \mathrm{Co}^{+}$is approximately four times poorer than that for ${ }^{165} \mathrm{Ho}^{+}$. The direction and magnitude of this mass bias effect are quite typical of that seen on most quadrupole ICP/MS instruments. In contrast, Table 3 also shows that the molar sensitivities for all three test elements increase to approximately $3 \times 10^{8}$ counts $s^{-1}$ $\mathrm{mM}^{-1}$ when interface B (Figure 3) is used with $+30 \mathrm{~V}$ on the skimmer. The process of floating the sampler

Table 3. Molar sensitivities for various elements expressed in terms of atomic concentration

\begin{tabular}{|c|c|c|c|}
\hline \multirow[b]{2}{*}{ Interface arrangernent } & \multicolumn{3}{|c|}{ Molar sensitivity (counts $\mathrm{s}^{-1} \mathrm{mM}^{-1}$ ) } \\
\hline & $\begin{array}{c}\text { Co } \\
(m / 259)\end{array}$ & $\begin{array}{c}\mathrm{Rh} \\
(\mathrm{m} / z \text { 103) }\end{array}$ & $\begin{array}{c}\mathrm{Ho} \\
(m / 2 \text { 165) }\end{array}$ \\
\hline $\begin{array}{l}\text { Sampler and skimmer } \\
\text { grounded } \\
\text { (Figure 2) }\end{array}$ & $5.6 \times 10^{7}$ & $8.5 \times 10^{7}$ & $2.2 \times 10^{8}$ \\
\hline $\begin{array}{l}\text { Sampler floated and } \\
\text { skimmer biased } \\
\text { (Figure } 3 b \text { at } 30 \mathrm{~V}\end{array}$ & $3.5 \times 10^{8}$ & $3.3 \times 10^{8}$ & $3.0 \times 10^{8}$ \\
\hline
\end{tabular}


and biasing the skimmer improves the sensitivity for $\mathrm{Co}^{+}$by a much greater factor (approximately sixfold) than is the case for the heavier $\mathrm{Ho}^{+}$. Thus, the mass bias effect is reduced to only moderate proportions, at least in the mass range studied ( $m / z$ 59-165).

Note that the interface arrangement that reduces mass bias problems (sampler floating, $+30 \mathrm{~V}$ on the skimmer) also yields the best ion transmission in Figure 5. For analytical purposes, minimizing the mass bias effect in this fashion greatly facilitates internal standardization and multielement semiquantitative analysis in that few reference elements are necessary to define the mass response curve [13].

\section{Ion Kinetic Energy}

In general, the ion energies for $\mathrm{Co}^{+}, \mathrm{Rh}^{+}$, and $\mathrm{Ho}^{+}$ increase as various parts of the interface are biased at positive voltages or floated. As an example, the influence of voltage applied to both sampler and skimmer together (i.e., interface A in Figure 3) on $\mathrm{Co}^{+}$energy is shown in Table 4. The kinetic energy increases with applied potential. Unfortunately, the power supply for the DC pole bias for the quadrupole could not be set above $+15 \mathrm{~V}$, so ion energies could not be measured above this value. To a first approximation, space charge effects should be mitigated as ion kinetic energy increases (i.e., as $V$ in eq 1 increases). Thus, some of the improvements observed could be due to reduction of the deleterious effects of space charge when the interface is floated.

It is interesting that the ion energy with the interface grounded directly to the vacuum chamber is different from that measured when the interface was grounded through the power supply $(0 \mathrm{~V})$. The ion sensitivities are also higher when the interface is grounded through the power supply, as shown by the points at $0 \mathrm{~V}$ in Figure 5.

\section{Voltage Measurements}

A voltmeter was used to measure the actual voltage present on the sampler and skimmer during operation. These measured voltages are compared with the voltage output by the power supply to either the sampler or the skimmer in Figures 7 and 8 . The curves in

Table 4. Influence of voltages applied to both sampler and skimmer together on $\mathrm{Co}^{+}$kinetic energies

\begin{tabular}{cc}
\hline Interface arrangement & $\begin{array}{c}\text { Maximum ion energy } \\
(\mathrm{eV}) \text { for }\end{array}{ }^{59} \mathrm{Co}^{+}$ \\
\hline \hline $\begin{array}{l}\text { Sampler and skimmer grounded } \\
\text { (Figure 2) }\end{array}$ \\
Sampler and skimmer biased \\
(V) (Figure 3a) \\
0 \\
10 \\
$>20$
\end{tabular}

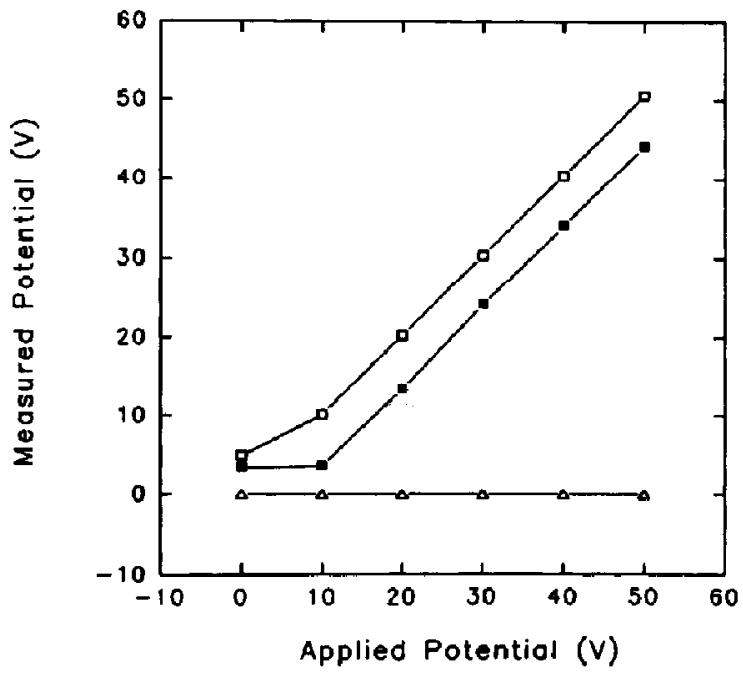

Figure 7. Measured potential on sampler as a function of applied bias potential with interface A (sampler and skimmer biased together, $\square$ ), interface $B$ (sampler floated and skimmer biased, $\square$ ), and interface $C$ (sampler grounded and skimmer biased, $\Delta$ ).

Figures 7 and 8 correspond to the interface arrangements illustrated earlier in Figure 3.

First, consider the case in which the sampler and skimmer are biased together. The voltage on the sampler (Figure 7, interface A) and that on the skimmer (Figure 8, interface A) both equal the applied voltage if

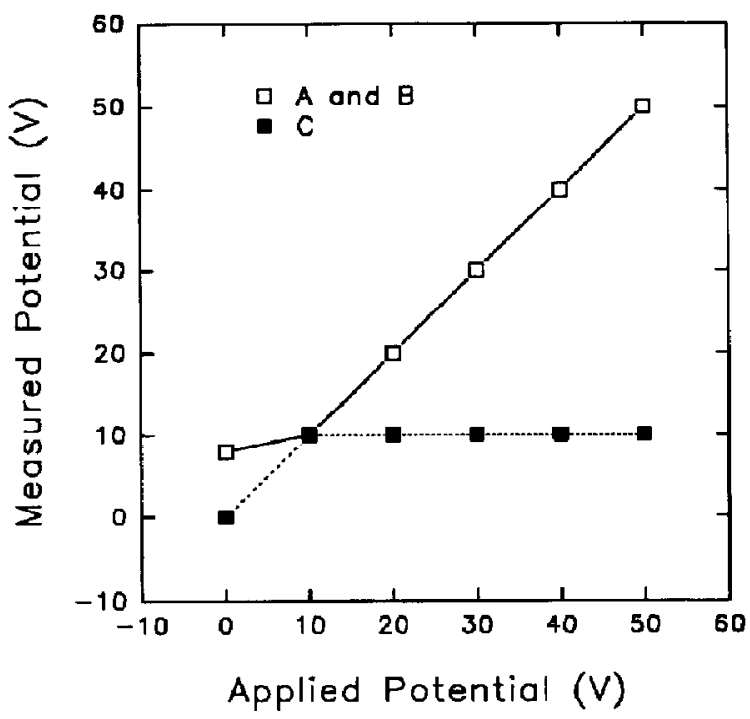

Figure 8. Measured potential on skimmer as a function of applied bias potential with interface $A$ (sampler and skimmer biased together), interface B (sampler floated and skimmer biased), and interface $C$ (sampler grounded and skimmer biased). 
the latter parameter is $10 \mathrm{~V}$ or higher. If $0 \mathrm{~V}$ is applied to the sampler or skimmer by the power supply, then the measured voltage is about +5 to $+7 \mathrm{~V}$ rather than zero. Apparently, the plasma causes current flow through the sampler or skimmer to the voltage supply. When set at $0 \mathrm{~V}$, the voltage supply could not accommodate this current, so the real voltage actually present on the sampler and skimmer differed from the setting on the voltage supply. This could explain the previous observations that (1) the sensitivity improves in Figure 3 when the sampler is "grounded" through the power supply rather than to the vacuum system; and (2) the maximum ion energy is $3 \mathrm{~V}$ higher when the sampler and skimmer are both "grounded" through the power supply rather than to the vacuum system (Table 4).

Next, consider the case where the sampler is floated and the skimmer is biased at $+10 \mathrm{~V}$ or higher (Figure 7 , interface B). Here, the measured voltage on the sampler is consistently $5 \mathrm{~V}$ lower than the voltage applied to the skimmer. This relationship between sampler and skimmer voltages suggests that there is an electrically conducting path between these two components: the flow of ions and electrons from the plasma through the sampling orifice to the skimmer. With $0 \mathrm{~V}$ on the skimmer, the measured voltage on the sampler is $+4 \mathrm{~V}$, which is $2 \mathrm{~V}$ lower than the measured voltage on the sampler when both sampler and skimmer are biased together at $0 \mathrm{~V}$ (Figure 7 , interface A).

Finally, the sampler was grounded to the vacuum system, and the skimmer was biased (Figures 7 and 8, interface C). In this case, the sampler voltage stays at zero and is independent of the voltage applied to the skimmer (Figure 7, interface C), as expected. The actual voltage measured at the skimmer limits at $+10 \mathrm{~V}$ (Figure 8 , interface $\mathrm{C}$ ), even if the power supply is set to deliver a higher voltage. This general behavior has been seen previously by other investigators who had difficulty biasing the skimmer to a DC voltage that was different from that on the sampler by more than a few volts [10].

The power supply used to bias the skimmer has a maximum current output of approximately $0.3 \mathrm{~A}$. The current carried by the flow of either ions or electrons through the sampler can be estimated as follows [1,2, 26]. The gas flow rate through a $1.3-\mathrm{mm}$ diameter aperture from an Ar ICP at $5000 \mathrm{~K}$ is approximately $1.5 \times 10^{21}$ atoms s$~^{-1}$. In the plasma, the number density of Ar atoms at this temperature is approximately $1.4 \times 10^{18} \mathrm{~cm}^{-3}$, whereas the number density of either ions or electrons is approximately $1 \times 10^{15} \mathrm{~cm}^{-3}$ at the center of the axial channel under typical ICP/MS conditions [34]. The flow rate of ions (or electrons) through the sampler is therefore approximately $1 \times 10^{18}$ ions $\mathrm{s}^{-1}$, assuming that ion-electron recombination is negligible. This corresponds to a current of $0.16 \mathrm{~A}$, which is only two times lower than the maximum current output of the power supply. Thus, it is reasonable that the voltage that can be applied to the skimmer (with the sampler grounded) limits at approximately $10 \mathrm{~V}$ because the current flow between the sampler and skimmer is comparable to the maximum output of the power supply.

\section{Conclusions}

This study demonstrates certain advantages to floating the sampler and/or skimmer in ICP/MS. Analyte signals and linear dynamic range are improved, and mass bias is diminished. The latter two problems are at least partly ascribable to space charge effects $[1,2]$. For example, as the concentration of a matrix element increases, the trajectories of both analyte ion and matrix ion are perturbed. A lower fraction of the matrix ions then travel through the lens successfully so that the calibration curve for the matrix ion rolls over because the matrix element suppresses its own transmission. Earlier work on a "cooled" ICP for potassium isotope ratio measurements also showed rollover in calibration curves for $\mathrm{K}^{+}$when the potassium concentration became high enough for $\mathrm{K}^{+}$to be one of the dominant ions in the spectrum [35], which supports this contention. Electrical effects during ion extraction, such as those described when Douglas [14, 15] applied RF bias to the sampler and/or skimmer, probably also contribute to the observations reported in this study.

At any rate, further basic studies, such as measurement of matrix effects for analyte elements [36], Langmuir probe experiments [11, 37-39], and, possibly, spatially resolved measurements of ion density behind the skimmer [40], are necessary to fully elucidate the fundamental reasons for the analytical improvements seen in this study. For example, it is not even known whether the beneficial effects of floating the interface derive from shanges to the plasma, to the supersonic jet between the sampler and skimmer, or to the beam leaving the skimmer. Perhaps the computer code for calculating ion trajectories under space charge conditions [2] could be modified to include the effects of floating the skimmer. The phenomena described in this study may be somewhat specific to the particular ion lens used (Figure 4). Hopefully, floating the interface will boost the analyte signal and reduce mass bias for the offset ion lens $[24,25]$ or other ion optical arrangements for ICP/MS. Such experiments are currently underway in our laboratory.

\section{Acknowledgments}

The Ames Laboratory is operated by lowa State University for the U.S. Department of Energy under Contract No. W-7405-Eng82. This research was supported by the U.S. Department of Commerce through the Center for Advanced Technology Development, Iowa State University. The ultrasonic nebulizer was provided by Cetac Technologies, Inc. We also thank A. Tokey from Thermo Jarrell-Ash for helpful discussions concerning the section on voltage measurements. 


\section{References}

1. Gillson, G. K.; Douglas, D. J.; Fulford, J. E; Halligan, K. W.; Tanner, S. D. Anal. Chem. 1988, 60, 1472-1474.

2. Tanner, S. D. Spectrochim. Acta 1992, 47B, 809-824.

3. Tan, S. H.; Horlick, G. J. Anal. Atom. Spectrom. 1987, 2, 745-763.

4. Beauchemin, D.; McLaren, J. W.; Berman, S. S. Spectrochim. Acta 1987, 42B, 467-490.

5. Kawaguchi, H.; Tanaka, T.; Mizuike, A. Spectrochim. Acta 1988, 43B, 955-962.

6. Pierce, J. R. Theory and Design of Electron Beams, 2nd ed; Van Nostrand: New York, 1954.

7. Bradshaw, N.; Hall, E. F. H.; Sanderson, N. E. I. Arul. Atom. Spectrom. 1989, 4, 801-803.

8. Morita, M.; Ito, H,; Uehiro, T.; Otsuka, K. Anal. Sci, (Japan) 1989, 5, 609-610.

9. Kim, C. K.; Seki, R.; Morita, S.; Yamasaki, S. I.; Tsumura, A.; Takaku, Y.; Igarashi, Y.; Yamamoto, M. J. Anal. Atom. Spectrom. 1991, 6, 205-209.

10. Gray, A. L. Private communications, 1985 and 1993.

11. Gray, A. L.; Houk, R. S.; Williams, J. L. J. Anal. Atom. Spectrom. 1987, 2, 13-20.

12. Hutton r. C; Eaton, A. N. J. Anal. Atom. Spectrom. 1987, 2, 595-598.

13. Turner, P. J. In Applications of Plasma Source Mass Spectrametry; Holland, G.; Eaton, A. N., Eds.; Thomas Graham House: Science Park, Cambridge, 1991.

14. Douglas, D. J. U.S. Patent Document, Patent No. 4682026.

15. Douglas, D. J. Can. I. Spectrose. 1989, 34, 38-49.

16. Douglas, D. J.; French, J. B. Spectrochim. Acta 1986, 41B, 197-204.

17. Houk, R. S.; Hu, K. U.S. Patent Application, Serial Nu. 07/888620, 1992.

18. Hu, K. Ph.D. Dissertation, Iowa State University, Ames, IA, 1992.

19. Olivares, J. A.; Houk, R. S. Amal. Chem. 1985, 57, 2674-2679.

20. Huang, L. Q; Jiang, S. J; Houk, R. S. Anal. Chem. 1987, 59, 2316-2320.
21. Crain, J. S.; Houk, R. S.; Eckels, D. E. Anal. Chem. 1989, 61, 606-612.

22. Olson, K. W.; Haas, W. J. Jr.; Fassel, V. A. Anal. Chem. 1977, $49,632-637$.

23. Bear, B. R.; Fassel, V. A. Spectrochim. Acta 1986, 47B, $1089-$ 1113.

24. Hu, K.; Clemons, P. S.; Houk, R. S. J. Am. Soc. Mass. Spectrom. $1993,4,16-27$.

25. Hu, K.; Houk, R. S. I. Am. Soc. Mass. Spectrom. 1993, 4, $28-37$.

26. Douglas, D. J.; French, J. B. J. Anal. Atom. Spectrom. 1988, 3, 743-747.

27. Jarvis, K. E.; Gray, A. L.; Houk, R. S. Handbook of Inductively Coupled Plasma Mass Spectrometry; Blackie: Glasgow, 1991; pp $33,45,157$.

28. Horlick, G.; Shao, Y. In Inductively Coupled Plasmas for Analyticul Atomic Spectromelry, 2nd ed,; Montaser, A.; Golightly. D., Eds,; VCH: New York, 1992, p 564.

29. Olivares, J. A.; Houk, R. S. Appl. Spectrosc. 1985, 39, 10701077.

30. Fulford, J. E.; Douglas, D. J. Appl. Spectrosc. 1986, 40, 971-974.

31. Chambers, D. M.; Hieftje, G. M. Spectrochim. Acta 1991, 46B, 761-784.

32. Houk, R. S. Anal. Chem. 1986, 58, 97A-105A.

33. Russ, G. P.; Bazan, J. M. Spectrochim. Acta 1987, 42B. 49-62.

34. Crain, J. 5.; Smith, F. G.; Houk, R. S. Spectrochim. Acta 1990, 249-259.

35. Jiang, S.-J.; Houk, R. S.; Stevens, M. A. Anal. Chem. 1988, 60, 1217-1221.

36. Tan, S. H.; Horlick, G. I. Anal. Atom. Spectrom. 1987, 2, 745-763.

37. Lim, H. B.; Houk, R. S; Crain, J. S. Spectrochim. Acta 1989, 44B, 989-998.

38. Lim, H. B.; Houk, R. S. Spectrochim. Acta 1990, 45B, 453-461.

39. Niu, H. S; Hu, K.; Houk, R. S. Spectrochim. Acta 1991, $46 B$, 805-817.

40. Chen, X.; Houk, R. S. Pittsburgh Conference on Analytical Chemistry and Applied Spectroscopy; Atlanta, GA, March 1993; paper 982. 